\title{
Technical Note: Volume Transport Equations in Combined Sverdrup- Stommel-Munk Dynamics without Level of no Motion
}

Peter C. Chu

Naval Ocean Analysis and Prediction Laboratory, Department of Oceanography

5 Naval Postgraduate School, Monterey, CA 93943, USA

Correspondence to: Peter C. Chu (pcchu@nps.edu)

Abstract. The cornerstone theories of ocean dynamics proposed by Sverdrup (1947), Stommel

10 (1948), and Munk (1950) are based on the assumption of level of no motion. Such an assumption is the same as the assumption of no meridional geostrophic transport. Ever since Sverdrup (1947) however, verification of the accuracy of the Sverdrup balance theory is based on the comparison of the Sverdrup meridional transport with the meridional transport calculated directly from the geostrophic currents based on hydrographic data. To overcome the mismatch between theory (no

15 meridional geostrophic transport in Sverdrup transport) and verification (comparison of Sverdrup transport to meridional geostrophic transport), extended Sverdrup-Stommel-Munk transport equations are derived in this note with replacing the level of no motion by the ocean bathymetry and in consequence one forcing function (surface wind stress) in the classical transport equations (with level of no motion assumption) is replaced by five forcing functions: density, surface wind stress, bottom meridional current, bottom stresses due to vertical and horizontal viscosities. The first two forcing functions (density and surface wind stress) are more than an order of magnitude stronger than the other three forcing functions using the world ocean bathymetry, climatological annual mean hydrographic and surface wind stress data. The extended Sverdrup volume transport streamfunctions under wind forcing, density forcing, and combined wind and density forcing are presented. 


\section{Introduction}

The seminal papers by Sverdrup (1947), Stommel (1948), and Munk (1950) laid the foundation of

30 wind-driven ocean circulation. Sverdrup balance (SB) represents the meridional volume transports employing only the local wind-stress in a linear dynamical framework (Wunsch 2011). Stommel (1948) and Munk (1950) linear frictional ocean models are used to explain the existence of intensive western boundary currents. Their theories were established on the base of an assumption of level of no motion $(H)$. What is the physics behind this assumption? What happens

35 if level of no motion does not exist?

Let the Cartesian coordinates be used with $(x, y)$ the horizontal and $z$ the vertical coordinates (upward positive) and (i, $\mathbf{j}, \mathbf{k})$ the corresponding unit vectors, and let the horizontal and vertical velocities be represented by $\mathbf{V}=(u, v, w)$. With low Rossby and Ekman numbers, steady state momentum and continuity equations are given by

$$
\begin{gathered}
-f \rho v=-\frac{\partial p}{\partial x}+\rho A_{z} \frac{\partial^{2} u}{\partial z^{2}}+\rho A_{h} \nabla^{2} u \\
f \rho u=-\frac{\partial p}{\partial y}+\rho A_{z} \frac{\partial^{2} v}{\partial z^{2}}+\rho A_{h} \nabla^{2} v \\
\rho g=-\frac{\partial p}{\partial z} \\
\frac{\partial(\rho u)}{\partial x}+\frac{\partial(\rho v)}{\partial y}+\frac{\partial(\rho w)}{\partial z}=0
\end{gathered}
$$

where $f=2 \Omega \sin \varphi$, is the Coriolis parameter, $\Omega$ the Earth rotation rate, and $\varphi$ the latitude; $\rho$ is the

45 density; $p$ is the pressure; $\left(A_{z}, A_{h}\right)$ are the vertical and horizontal eddy viscosities; $\nabla=\mathbf{i} \partial / \partial x+\mathbf{j} \partial / \partial y$, is the horizontal gradient operator. Vertical integration of the horizontal 
Ocean Sci. Discuss., doi:10.5194/os-2016-81, 2016

Manuscript under review for journal Ocean Sci.

Published: 1 November 2016

(c) Author(s) 2016. CC-BY 3.0 License.

momentum equations (1a) and (1b) with respect to $z$ from a depth $z=-H(x, y)$ to the surface leads

to

$$
\begin{aligned}
& -A_{h} \nabla^{2} M_{x}-f M_{y}=-\int_{-H}^{0} \frac{\partial p}{\partial x} d z+\tau_{x}-\tau_{x}^{(b)}-A_{h} \rho_{0} Q_{x} \\
& -A_{h} \nabla^{2} M_{y}+f M_{x}=-\int_{-H}^{0} \frac{\partial p}{\partial y} d z+\tau_{y}-\tau_{y}^{(b)}-A_{h} \rho_{0} Q_{y}
\end{aligned}
$$

where

$$
M_{x}=\int_{-H}^{0} \rho u d z, M_{y}=\int_{-H}^{0} \rho v d z
$$

are the zonal and meridional transports, which satisfy

$$
\frac{\partial M_{x}}{\partial x}+\frac{\partial M_{y}}{\partial y}=0 .
$$

55 The vectors

$$
\begin{gathered}
\left(\tau_{x}, \tau_{y}\right)=\left.\rho_{0} A_{z}\left(\frac{\partial u}{\partial z}, \frac{\partial v}{\partial z}\right)\right|_{z=0} \\
\left(\tau_{x}^{(b)}, \tau_{y}^{(b)}\right)=\left.\rho_{0} A_{z}\left(\frac{\partial u}{\partial z}, \frac{\partial v}{\partial z}\right)\right|_{z=-H(x, y)}=\left\{\begin{array}{l}
C_{D} \rho_{0} \sqrt{u_{-H}^{2}+v_{-H}^{2}}\left(u_{-H}, v_{-H}\right), \quad \text { Drag law } \\
R\left(M_{x}, M_{y}\right), \quad \text { Rayleigh friction }
\end{array}\right. \\
\left(Q_{x}, Q_{y}\right)=\left[\left(2 \nabla u_{-H} \bullet \nabla H+u_{-H} \nabla^{2} H\right),\left(2 \nabla v_{-H} \bullet \nabla H+v_{-H} \nabla^{2} H\right)\right],
\end{gathered}
$$

represent wind stress, bottom stress due to vertical eddy viscosity, and bottom stress due to

60 horizontal viscosity. Here, $\left(u_{-H}, v_{-H}\right)$ are the current velocities at depth $z=-H ; \rho_{0}\left(=1028 \mathrm{~kg} / \mathrm{m}^{3}\right)$ is the characteristic density.

If $z=-H$ is a level of no motion, $\left(u_{-H}, v_{-H}\right)=0$ (also implying no stress at this level, i.e., $\boldsymbol{\tau}^{(\mathrm{b})}$ $=0$ if the drag law is used) and the $P$ function in Sverdrup (1947) 
Ocean Sci. Discuss., doi:10.5194/os-2016-81, 2016

Manuscript under review for journal Ocean Sci.

Published: 1 November 2016

(c) Author(s) 2016. CC-BY 3.0 License.

$$
\frac{\partial P}{\partial x}=\int_{-H(x, y)}^{0} \frac{\partial p}{\partial x} d z, \quad \frac{\partial P}{\partial y}=\int_{-H(x, y)}^{0} \frac{\partial p}{\partial y} d z
$$

65 exists.

Under the condition (8) (i.e., existence of the $P$ function) cross differentiation of (3) and (4) will make disappearance of the horizontal pressure gradient terms and give the classical Sverdrup balance (SB) if no horizontal viscosity $\left(A_{h}=0\right)$,

$$
\beta M_{y}=\operatorname{curl}(\tau)
$$

70 If $z=-H$ is not a level of no motion, the $P$ function does not exist. This is because

$$
\begin{aligned}
& \frac{\partial}{\partial y}\left(\frac{\partial P}{\partial x}\right)=\left.\frac{\partial p}{\partial x}\right|_{-H(x, y)} \frac{\partial H}{\partial y}+\int_{-H(x, y)}^{0} \frac{\partial^{2} p}{\partial x \partial y} d z, \\
& \frac{\partial}{\partial x}\left(\frac{\partial P}{\partial y}\right)=\left.\frac{\partial p}{\partial y}\right|_{-H(x, y)} \frac{\partial H}{\partial x}+\int_{-H(x, y)}^{0} \frac{\partial^{2} p}{\partial x \partial y} d z .
\end{aligned}
$$

This leads to an impossible relationship

$$
\frac{\partial}{\partial y}\left(\frac{\partial P}{\partial x}\right) \neq \frac{\partial}{\partial x}\left(\frac{\partial P}{\partial y}\right)
$$

Cross differentiation of (3) and (4) without a level of no motion leads to a revised Sverdrup

75 transport equation,

$$
\beta M_{y}=\left[\frac{\partial}{\partial y} \int_{-H}^{0} \frac{\partial p}{\partial x} d z-\frac{\partial}{\partial x} \int_{-H}^{0} \frac{\partial p}{\partial y} d z\right]+\operatorname{curl}(\boldsymbol{\tau})-\operatorname{curl}\left(\boldsymbol{\tau}^{(b)}\right)
$$

Substitution of the geostrophic balance

$$
f \rho u_{g}=-\frac{\partial p}{\partial y}, f \rho v_{g}=\frac{\partial p}{\partial x}
$$

into (12) gives

$$
\beta M_{y}=\beta M_{y}^{(g)}+\operatorname{curl}(\tau)-\operatorname{curl}\left(\tau^{(b)}\right)
$$

where 


$$
M_{y}^{(g)}=\int_{-H}^{0} \rho v_{g} d z=\frac{1}{f} \int_{-H}^{0} \frac{\partial p}{\partial x} d z
$$

Comparison between (9) and (14) leads to the fact that existence of a level of no motion is the same as vanish of meridional geostrophic transport in the system,

$$
M_{y}^{(g)}=0 .
$$

However, verification of the accuracy of the SB theory is based on the comparison of the Sverdrup meridional transport (i.e., the surface wind stress curl) with the meridional transport calculated directly from the geostrophic currents based on hydrographic data (i.e., the meridional geostrophic transport). The first was that of Leetmaa et al. [1977], followed by the studies of Wunsch and Roemmich [1985], Böning et al. [1991], Schmitz et al. [1992], etc. Their results have shown that the Sverdrup meridional transport is generally consistent with the meridional transport calculated directly from the geostrophic currents based on hydrographic data in the northeastern subtropical North Atlantic Ocean, but is inconsistent with the geostrophic transports in the northwestern subtropical North Atlantic Ocean. Meyers [1980] discussed the meridional transport of North Equatorial Countercurrent in the equatorial Pacific and found significant inconsistency with the Sverdrup theory. Hautala et al. [1994] estimated the meridional transport of the North Pacific subtropical gyre along $24^{\circ} \mathrm{N}$ and noted that the Sverdrup balance is not valid in the western subtropical Pacific Ocean. Lately, Wunsch [2011] has evaluated the accuracy of the Sverdrup theory using an assimilated global ocean dataset.

A logical way to overcome such a mismatch between SB theory (no meridional geostrophic transport) and verification (comparison of surface wind stress curl to meridional geostrophic transport) is to remove the level of no motion and instead to use a known level. The ocean bottom [i.e., $z=-H(x, y)]$ is a reasonable choice. Therefore, $H$ is referred to the ocean bottom depth here 
after. Questions arise: How do the Sverdrup-Stommel-Munk equations change after $H$ is changed from the level of no motion to the ocean bottom depth? What is new physics behind such a change? This note will answer these questions. Following the same path as SB from (9) to (14), several new volume transport equations (called extended Sverdrup-Stommel-Munk equations) have been derived. The rest of the note is outlined as follows. Section 2 presents extended SverdrupStommel-Munk transport equations. Section 3 depicts the world ocean climatological annual mean

110 forcing functions. Section 4 shows the world ocean climatological annual mean density and wind driven Sverdrup transport streamfunctions. Section 5 gives the summary.

\section{Extended Sverdrup-Stommel-Munk Transport Equations}

\subsection{Geostrophic Currents under Boussinesq Approximation}

With the Boussinesq approximation, vertical differentiation of (13) and use of hydrostatic balance

115 (1c) leads to the thermal wind relation,

$$
\frac{\partial u_{g}}{\partial z}=\frac{g}{f \rho_{0}} \frac{\partial \rho}{\partial y}, \frac{\partial v_{g}}{\partial z}=-\frac{g}{f \rho_{0}} \frac{\partial \rho}{\partial x}
$$

Vertical integration of (17) from the ocean bottom $[z=-H(x, y)]$ to any depth $z$ leads to the calculation of the geostrophic currents from the density $\rho$,

$$
\begin{aligned}
& u_{g}=u_{-H}+\frac{g}{f \rho_{0}} \int_{-H}^{z} \frac{\partial \rho}{\partial y} d z^{\prime}, \\
& v_{g}=v_{-H}-\frac{g}{f \rho_{0}} \int_{-H}^{z} \frac{\partial \rho}{\partial x} d z^{\prime} .
\end{aligned}
$$

\subsection{Volume Transport Equations}

Cross differentiation of (3) and (4) leads to the transport equation for the whole water column,

$$
-A_{h} \nabla^{4} \Psi+\beta \frac{\partial \Psi}{\partial x}=\beta V_{d e n}+\beta H v_{-H}+\frac{\operatorname{curl} \boldsymbol{\tau}}{\rho_{0}}-\frac{\operatorname{curl} \boldsymbol{\tau}^{(b)}}{\rho_{0}}-A_{h}\left(\frac{\partial Q_{y}}{\partial x}-\frac{\partial Q_{x}}{\partial y}\right)
$$


where $\Psi$ is the volume transport streamfunction

$$
M_{x}=-\rho_{0} \frac{\partial \Psi}{\partial y}, \quad M_{y}=\rho_{0} \frac{\partial \Psi}{\partial x}
$$

$V_{d e n}$ is the meridional geostrophic transport

$$
V_{d e n}=-\frac{g}{f \rho_{0}} \int_{-H}^{0} \int_{-H}^{z} \frac{\partial \rho}{\partial x} d z^{\prime} d z
$$

When the Rayleigh friction is used for the bottom stress (7b), Eq.(20) becomes the extended MunkStommel model,

$$
-A_{h} \nabla^{4} \Psi+R \nabla^{2} \Psi+\beta \frac{\partial \Psi}{\partial x}=\beta V_{d e n}+\beta H v_{-H}+\frac{\operatorname{curl} \tau}{\rho_{0}}-A_{h}\left(\frac{\partial Q_{y}}{\partial x}-\frac{\partial Q_{x}}{\partial y}\right)
$$

When the Rayleigh friction is used for the bottom stress (7b) and horizontal viscosity vanishes $\left(A_{h}\right.$ =0), Eq.(20) becomes the extended Stommel model,

$$
R \nabla^{2} \Psi+\beta \frac{\partial \Psi}{\partial x}=\beta V_{d e n}+\beta H v_{-H}+\frac{\operatorname{curl} \tau}{\rho_{0}}
$$

When $A_{h} \neq 0$, and the drag law is used for the bottom stress due to vertical viscosity, $\mathrm{Eq}(20)$

135 reduces to the extended Sverdrup transport equation,

$$
\beta \frac{\partial \Psi}{\partial x}=\beta V_{d e n}+\beta H v_{-H}+\frac{\operatorname{curl} \boldsymbol{\tau}}{\rho_{0}}-\frac{\operatorname{curl} \boldsymbol{\tau}^{(b)}}{\rho_{0}}-A_{h}\left(\frac{\partial Q_{y}}{\partial x}-\frac{\partial Q_{x}}{\partial y}\right) .
$$

\section{Forcing Functions}

Various transport equations (20), (23), (24), and (25) show that the volume transport is generated by density $\left(\beta V_{d e n}\right)$, bottom meridional current $\left(\beta H v_{-H}\right)$, wind stress curl $\left[(\operatorname{curl} \tau) / \rho_{0}\right]$, bottom 140 stress curl due to vertical viscosity $\left[\left(\operatorname{curl} \tau^{(b)}\right) / \rho_{0}\right]$ and horizontal viscosity $\left[A_{h}\left(\partial Q_{y} / \partial x-\partial Q_{x} / \partial y\right)\right]$. The density forcing function is further calculated by 


$$
\beta V_{d e n}=-\frac{g}{R_{E} \rho_{0}} \cot \phi \int_{-H}^{0} \int_{z}^{0} \frac{\partial \rho}{\partial x} d z^{\prime} d z, \quad \beta=\frac{2 \Omega}{R_{E}} \cos \phi, \quad \Omega=2 \pi / 86400 \mathrm{~s}^{-1}, R_{E}=6370 \mathrm{~km}
$$

The last three forcing functions depend on the bottom current velocities $\left(u_{-H}, v_{-H}\right)$ [see $(7 \mathrm{~b}),(7 \mathrm{c})$ and (20)], horizontal diffusivity $A_{h}$, and the bottom drag coefficient $C_{D}$. The P-vector inverse method (Chu 1995, 2000, Chu et al. 1998a, b) is used to determine $\left(u_{-H}, v_{-H}\right)$ from hydrographic data. The horizontal diffusivity $\left(A_{h}\right)$ is taken the value of $1.5 \times 10^{3} \mathrm{~m}^{2} \mathrm{~s}^{-1}$ by Smargrinsky parameterization and the bottom drag coefficient $C_{D}$ is set as 0.0025 (see Chu and Fan, 2007).

In this study, the five forcing functions are calculated from the three global datasets: (1) climatological annual mean hydrographic data downloaded from the NOAA 's World Ocean Atlas

1502013 at the website: http://www.nodc.noaa.gov/OC5/woa13/ for computing $\left(U_{d e n}, V_{d e n}\right)$ [see (17)], (2) the NOAA 's ETOPO5 from the website: http://www.ngdc.noaa.gov/mgg/global/etopo5.HTML for bottom topography $H(x, y)$, and (3) the Comprehensive Ocean-Atmosphere Data Set (COADS) at http://iridl.ldeo.columbia.edu/SOURCES/.DASILVA/.SMD94/.climatology/ for computing climatological annual mean surface wind stress $\left(\tau_{x}, \tau_{y}\right)$. than the wind forcing function $(\operatorname{curl} \tau) / \rho_{0}$ (Fig. 2). The root-mean-square (RMS) is $2.81 \times 10^{-10}$ $\mathrm{m} / \mathrm{s}^{2}$ for $\beta V_{\text {den }}$ and $6.16 \times 10^{-11} \mathrm{~m} / \mathrm{s}^{2}$ for $(\operatorname{curl} \boldsymbol{\tau}) / \rho_{0}$. The other three forcing functions are much smaller. Fig 3 shows the bottom stress forcing function due to horizontal viscosity $\left[A_{h}\left(\partial Q_{y} / \partial x-\partial Q_{x} / \partial y\right)\right]$ with the RMS of $3.32 \times 10^{-12} \mathrm{~m} / \mathrm{s}^{2}$, which is almost two-orders of

160 magnitude smaller than the density forcing. The computation shows the following relationship,

$$
\begin{aligned}
& \left\{\left[\operatorname{RMS}\left(\beta H v_{-H}\right), \operatorname{RMS}\left[\operatorname{curl} \boldsymbol{\tau}^{(b)} / \rho_{0}\right], \operatorname{RMS}\left[A_{h}\left(\partial Q_{y} / \partial x-\partial Q_{x} / \partial y\right)\right]\right\}\right. \\
& \ll \operatorname{RMS}\left[\operatorname{curl} \boldsymbol{\tau} / \rho_{0}\right]<\operatorname{RMS}\left[\beta V_{d e n}\right]
\end{aligned}
$$


Besides, the correlation coefficient between $\beta V_{\text {den }}$ and $\left(\operatorname{curl} \boldsymbol{\tau}^{(b)}\right) / \rho_{0}$ is 0.0699 , which implies the independence between the meridional geostrophic transport for the whole water column and the surface wind tress curl.

\section{Density and Wind Driven Sverdrup Transport Streamfunctions}

The extended Sverdrup Transport equation due to density and wind forcing [vanish of other three forcing functions in (25)] is given by

$$
\beta \frac{\partial \Psi}{\partial x}=\beta V_{d e n}+\frac{\operatorname{curl} \tau}{\rho_{0}}
$$

If wind forcing vanishes, the density driven Sverdrup transport streamfunction is calculated by

$$
\frac{\partial \Psi_{d e n}}{\partial x}=V_{d e n}
$$

If density forcing vanishes, the wind driven Sverdrup transport streamfunction is determined by

$$
\beta \frac{\partial \Psi_{w}}{\partial x}=\frac{\operatorname{curl} \tau}{\rho_{0}}
$$

which is the classical Sverdrup dynamics but the volume transport is for the whole water column rather than above a level of no motion. It is noted that in calculating the density forcing function

$175 \beta V_{d e n}$ in (28) and (29), the latitude $\phi$ is set as $15^{\circ} \mathrm{N}$ for the zonal region of $0^{\circ}-15^{\circ} \mathrm{N}$, and as $15^{\circ} \mathrm{S}$ for the zonal region of $0^{\circ}-15^{\circ} \mathrm{S}$ [see (26)]. With the climatological annual mean density and wind forcing functions calculated in Scetion 3, the three Sverdrup transport euqations (28)-(30) are solved using the traditional method with $\Psi=0$ at the east boudary and integrating westward to get the climatological annual mean density driven Sverdrup transport $\Psi_{\text {den }}$ (Fig. 4), wind driven

180 Sverdrup transport $\Psi_{w}$ (Fig. 5), and density-wind driven Sverdrup transport $\Psi$ (Fig. 6).

Since the purpose of this note is to present the extended transport equations after removing level of no-motion rather than to simulate the volume transports, only major features on $\left(\Psi_{d e n}, \Psi_{w}\right.$, 
$\Psi)$ are discussed. Although the density and wind forcing functions are very different (Fig. 1 and Fig. 2) with low correlation coefficient (0.0699), the three Sverdrup transport streamfunctions

$185\left(\Psi_{d e n}, \Psi_{w}, \Psi\right)$ show similar patterns in both hemispheres, i.e., subpolar gyre, subtropical gyre, equatorial current, and equatorial counter current. The volume transport driven by density $\left(\Psi_{d e n}\right)$ is stronger than driven by wind $\left(\Psi_{w}\right)$. The correlation coefficient is 0.185 between $\Psi_{d e n}$ and $\Psi_{w}, 0.716$ between $\Psi_{d e n}$ and $\Psi$, and 0.698 between $\Psi_{w}$ and $\Psi$.

\section{Summary}

190 The seminal theories by Sverdrup (1947), Stommel (1948), and Munk (1950) are established on the assumption of level of no motion. This note shows that this assumption is equivalent to the assumption of no meridional geostrophic transport. To remove the level of no motion and instead to use bottom topography, extended Sverdrup-Stommel-Munk transport equations are derived in this note with adding four more forcing functions in addition to the surface wind stress: density, bottom meridional current, bottom stresses due to vertical and horizontal viscosities. The density and wind forcing functions are dominant using the world ocean bathymetry, climatological annual mean hydrographic and surface wind stress data. The density and wind forcing functions are independent with very low correlation coefficient (0.0699). However, the Sverdrup transport streamfunctions under density, wind, and both forcing show similar patterns in both hemispheres,

200 i.e., subpolar gyre, subtropical gyre, equatorial current, and equatorial counter current. The correlation coefficient is 0.185 between density and wind forced Sverdrup transports; 0.716 between density and density-wind forced Sverdrup transports; and 0.698 between wind and density-wind forced Sverdrup transports.

\section{Acknowledgments}


Ocean Sci. Discuss., doi:10.5194/os-2016-81, 2016

Manuscript under review for journal Ocean Sci.

Published: 1 November 2016

(c) Author(s) 2016. CC-BY 3.0 License.

205 The author thanks Mr. Chenwu Fan's outstanding efforts on computational assistance, NOAA National Centers for Environmental Information (NCEI) for World Ocean Atlas 2013, bathymetry data, and Atlas of Surface Marine Data.

\section{References}

Böning, C. W., R. Döscher, and H. J. Isemer (1991), Monthly mean wind stress and Sverdrup 210 transports in the North Atlantic: a comparison of the Hellerman-Rosenstein and Isemer-Hasse Climatologies, J Phys Oceanogr., 21(2), 221-235.

Chu, P.C. (1995): P-vector method for determining absolute velocity from hydrographic data. Mar. Tech. Soc. J., 29 (3), 3-14.

Chu, P.C. (2000): P-vector spirals and determination of absolute velocities. J. Oceanogr., 56, 591599.

Chu, P.C., C.W. Fan, C.J. Lozano, and J. Kerling (1998): An AXBT survey of the South China 220 Sea. J. Geophy. Res., 103, 21637-21652.

Chu, P.C., and R.F. Li (2000): South China Sea isopycnal surface circulations. J. Phys. Oceanogr., 30, 2419-2438.

225 Chu, P.C., and C.W. Fan, 2007: An inverse model for calculation of global volume transport from wind and hydrographic data. J. Marine Syst., 65, 376-399.

Hautala, S. L., D. H. Roemmich, and W. J. Schmitz, Jr (1994), Is the North Pacific in Sverdrup Balance along $24^{\circ}$ N? J. Geophys. Res., 99, 16041-16052.

Leetmaa, A., P. Niiler, and H. Stommel (1977), does the Sverdrup relation account for the midAtlantic circulation? J. Mar. Res., 35, 1-10.

Meyers, G. (1980), Do Sverdrup transports account for the Pacific North Equatorial 235 Countercurrent, J. Geophys. Res., 85(2), 1073-1075.

Munk, W.H. (1950): On the wind-driven ocean circulation. J. Meteor., 7, 79-93.

Schmitz, W. J. Jr., J. D. Thompson, and J. R. Luyten (1992), The Sverdrup circulation for the 240 Atlantic along $24^{\circ} \mathrm{N}$, J. Geophys. Res., 97(5), 7251-7256.

Stommel, H. (1948), The westward intensification of wind-driven ocean currents. Trans. Amer. Geophys. Union, 29 (2), 202-206. 
Ocean Sci. Discuss., doi:10.5194/os-2016-81, 2016

Manuscript under review for journal Ocean Sci.

Published: 1 November 2016

(c) Author(s) 2016. CC-BY 3.0 License.

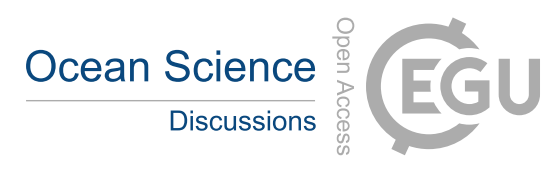

(c) (i)

245 Sverdrup, H. U. (1947), Wind-driver currents in a baroclinic ocean; with application to the equatorial current of the eastern Pacific, Proc. Natl. Acad. Sci., 33, 318-326.

Wunsch, C., and D. Roemmich (1985), Is the North Atlantic in Sverdrup Balance? J. Phys. Oceanogr., 15, 1876-1880.

250

Wunsch, C. (2011), the decadal mean ocean circulation and Sverdrup balance, J. Mar. Res., 69, 417-434. 
Ocean Sci. Discuss., doi:10.5194/os-2016-81, 2016

Manuscript under review for journal Ocean Sci.

Published: 1 November 2016

(c) Author(s) 2016. CC-BY 3.0 License.

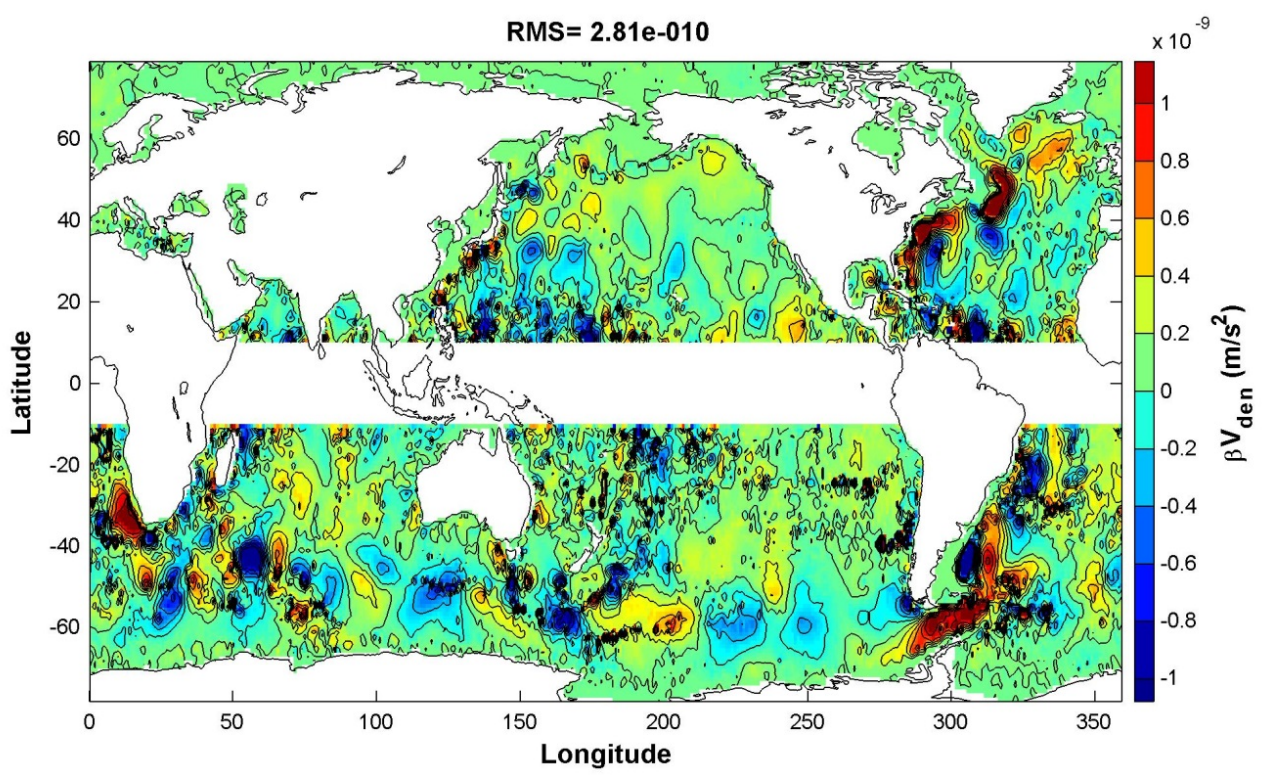

Fig. 1. Climatological annual mean density forcing $\beta V_{\text {den }}$ (unit: $\mathrm{m} / \mathrm{s}^{2}$ ) calculated from the NOAA/NCEI WOA13 data.

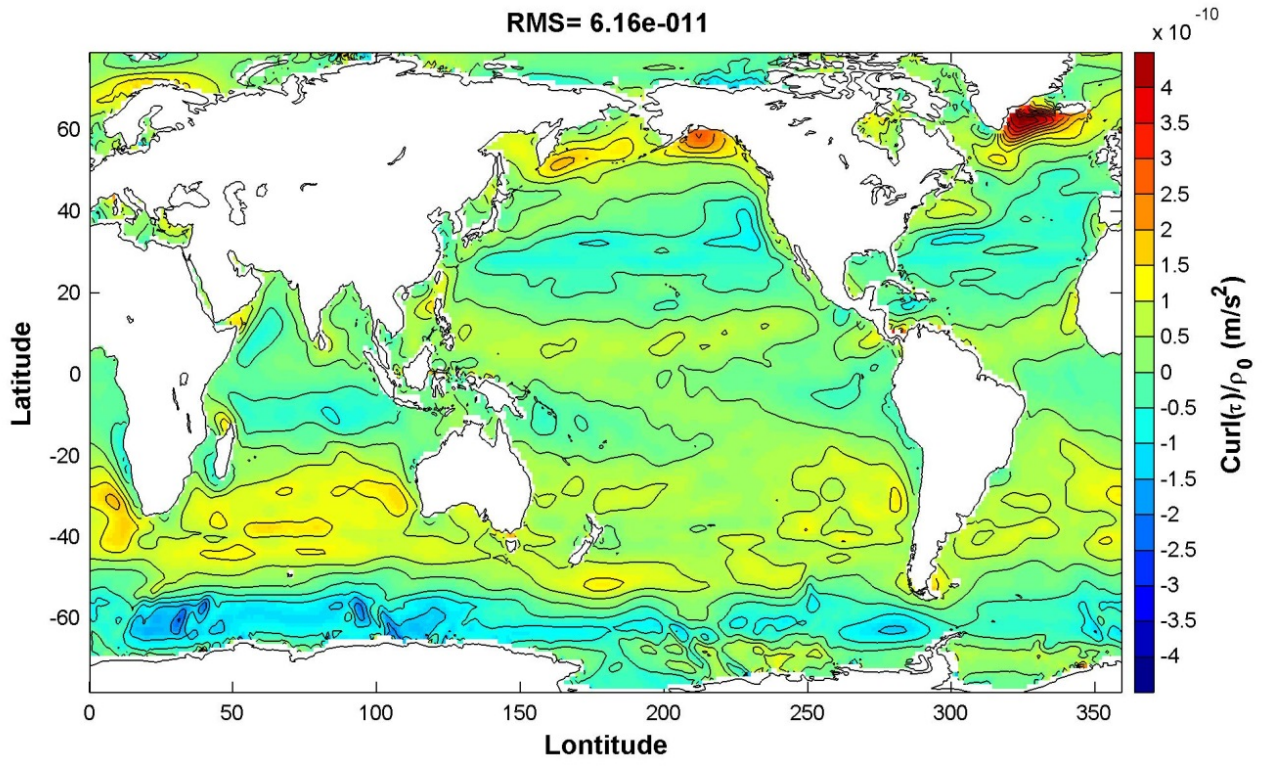

Fig. 2. . Climatological annual mean surface wind forcing $\left[(\operatorname{curl} \tau) / \rho_{0}\right]\left(\right.$ unit: $\left.\mathrm{m} / \mathrm{s}^{2}\right)$ calculated using the COADS data 
Ocean Sci. Discuss., doi:10.5194/os-2016-81, 2016

Manuscript under review for journal Ocean Sci.

Published: 1 November 2016

(c) Author(s) 2016. CC-BY 3.0 License.

(c) (1)

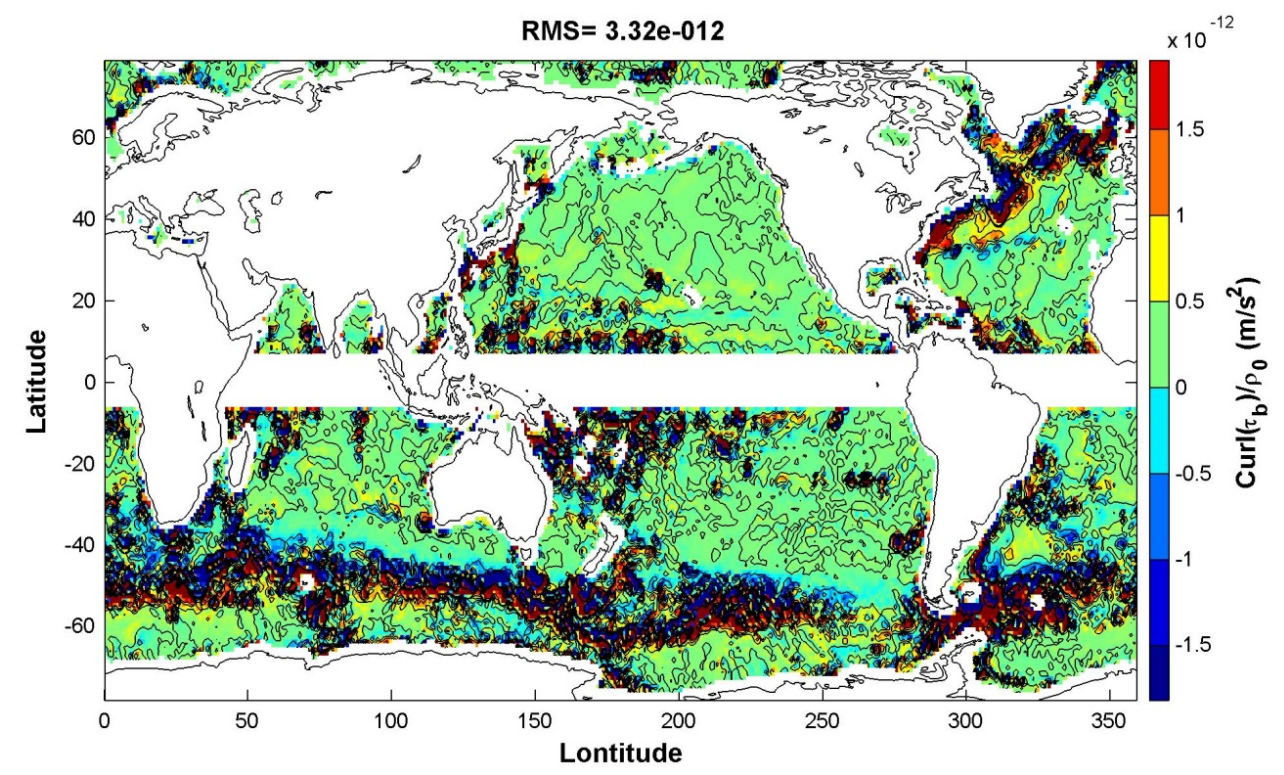

Fig. 3. Climatological annual mean bottom stress forcing due to horizontal viscosity $\left[A_{h}\left(\partial Q_{y} / \partial x-\partial Q_{x} / \partial y\right)\right]$ (unit: $\left.\mathrm{m} / \mathrm{s}^{2}\right)$ calculated from the NOAA/NCEI WOA13 data using the Pvector method and NOAA ETOPO5 data.

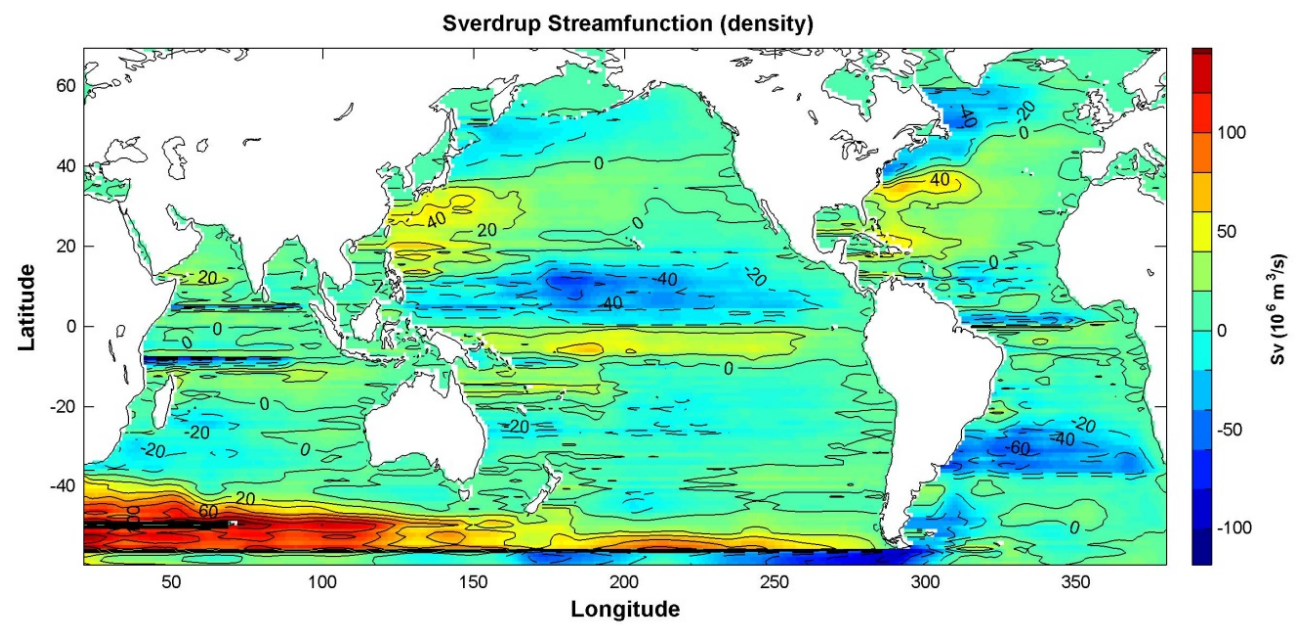

Fig. 4. Climatological annual mean density driven Sverdrup transport streamfunction (unit: $\mathrm{S}_{\mathrm{V}}=$ $10^{6} \mathrm{~m}^{3} / \mathrm{s}$ ). It is noted that in calculating the density forcing function $\beta V_{d e n}$, the latitude $\phi$ is set as $15^{\circ} \mathrm{N}$ for the zonal region of $0^{\circ}-15^{\circ} \mathrm{N}$, and as $15^{\circ} \mathrm{S}$ for the zonal region of $0^{\circ}-15^{\circ} \mathrm{S}$. 
Ocean Sci. Discuss., doi:10.5194/os-2016-81, 2016

Manuscript under review for journal Ocean Sci.

Published: 1 November 2016

(c) Author(s) 2016. CC-BY 3.0 License.

(c) (1)

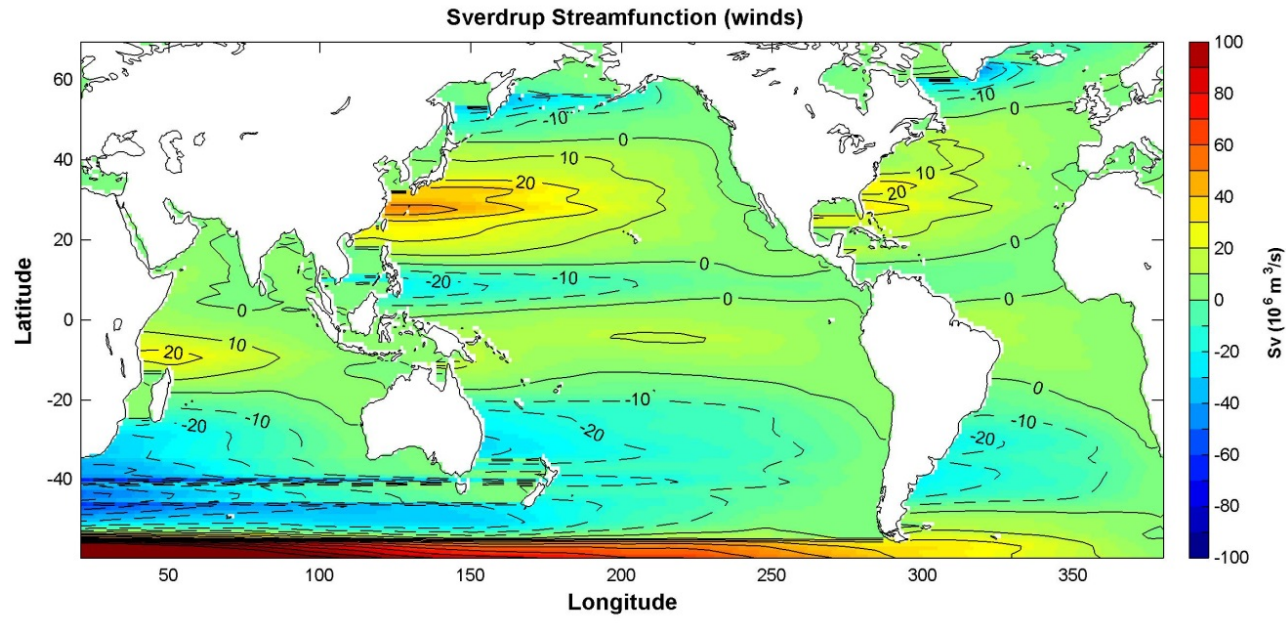

Fig.5. Climatological annual mean wind driven Sverdrup transport streamfunction (unit: $\mathrm{S}_{\mathrm{V}}=10^{6}$ $\left.\mathrm{m}^{3} / \mathrm{s}\right)$.

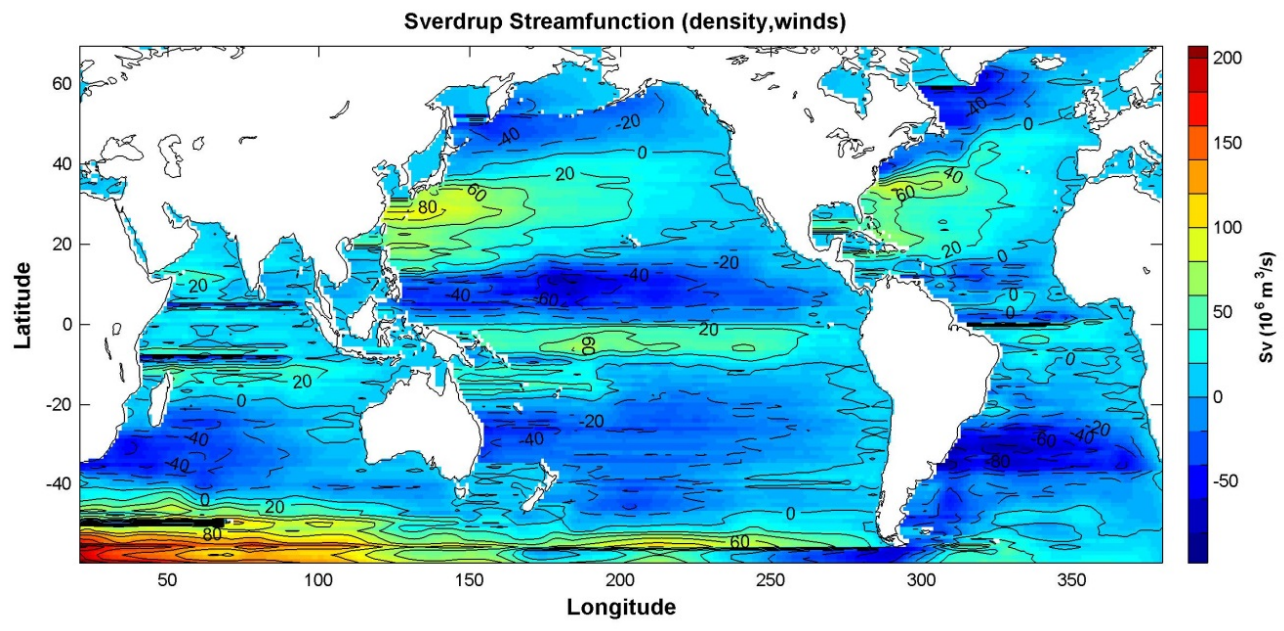

Fig. 6. Climatological annual mean density and wind driven Sverdrup transport streamfunction (unit: $\mathrm{S}_{\mathrm{V}}=10^{6} \mathrm{~m}^{3} / \mathrm{s}$ ). It is noted that in calculating the density forcing function $\beta V_{\text {den }}$, the latitude $\phi$ is set as $15^{\circ} \mathrm{N}$ for the zonal region of $0^{\circ}-15^{\circ} \mathrm{N}$, and as $15^{\circ} \mathrm{S}$ for the zonal region of $0^{\circ}-15^{\circ} \mathrm{S}$. 